\title{
Physical and Chemical Characterization of Chinese Maize Stalk Leaf Ash: Calcining Temperature and Aqueous Solution
}

\author{
Guorui Feng, ${ }^{\text {a,c }}$ Tingye Qi ${ }^{\mathrm{a}, \mathrm{b}, \mathrm{c}, *}$ Zehua Wang, ${ }^{\mathrm{a}, \mathrm{c}}$ Jinwen Bai ${ }^{\mathrm{a}, \mathrm{c}}$ and Zhen $\mathrm{Li}^{\mathrm{a}}{ }^{\mathrm{a}, \mathrm{c}}$
}

\begin{abstract}
This study focused on the physical and chemical characterization of Chinese maize stalk leaf ash (MSLA) calcined at 500,700 , and $850{ }^{\circ} \mathrm{C}$ and MSLA residual leaching in aqueous solutions. The grain size distribution, chemical composition, and microstructure of MSLA were investigated using a laser Mastersizer, X-ray fluorescence, and scanning electron microscopy. The ash samples obtained before and after dissolving were analyzed using X-ray powder diffraction and X-ray photoelectron spectroscopy to identify the present minerals and observe the $2 p$ atomic orbit of surface silicon and aluminum ( $\mathrm{Si} 2 \mathrm{p}$ and $\mathrm{Al} 2 \mathrm{p}$ ) transformation behaviors. The zeta potential and $\mathrm{pH}$ values of hybrid solutions were tested for various dissolving times. Silica was the predominant component observed in the MSLA. As dissolving time increased, the $\mathrm{pH}$ value gradually decreased, and the zeta potentials first slightly decreased and then remarkably increased. Quartz was identified in the MSLA. Another polymorphous crystalline form of silica, cristobalite, only appeared in the $850^{\circ} \mathrm{C}$ sample. The binding energies of Si $2 p$ and Al $2 p$ shifted, which transformed the XPS peaks after the thermal and aqueous solution treatment of MSLA. These findings can be utilized to study the application potential of MSLA in cementing systems.
\end{abstract}

Keywords: Maize stalk leaf ash; Calcination temperature; Aqueous solution; Silica

Contact information: a: College of Mining Technology, Taiyuan University of Technology, Taiyuan, China; b: State Key Laboratory of Coal Resources and Safe Mining, China University of Mining and Technology, Xuzhou, China; c: Shanxi Province Research Center of Green Mining Engineering Technology, Taiyuan, China; *Corresponding author: qty198402@163.com

\section{INTRODUCTION}

Biomass as fuel is mainly used to generate electricity and provide heat. In 2020, the projected biomass output produced for direct combustion power generation will be approximately $1.4 \times 10^{7} \mathrm{t}$. China is the most prominent crop-producing region of the world and produces a large amount of biomass waste every year, especially maize waste. The gross weight of maize straw is approximately 2.4 billion $t$, which accounts for $24.2 \%$ of the total crop output in China (Vassilev et al. 2013a; Zhang et al. 2016). Moreover, the maize stalk is a primary source of fuel for biomass power plants. The elements in maize stalk ash are primarily $\mathrm{Si}, \mathrm{K}, \mathrm{Ca}$, and $\mathrm{Mg}$ (Xiong et al. 2010). The disposal and use of the large maize ash waste from a power plant must be considered. Biomass ash has been reused in many ways, such as for removing methylene blue from water (Liu et al. 2018), producing geopolymers due to the silica content (Zarina et al. 2013), and applications in construction.

Biomass ash has been widely used as the raw material to improve the rheological properties of grout and the mechanics of the solidification bodies for cement-based 
materials. Moreover, the pozzolanic activity and negative surface charge of biomass ash have been considered (Givi et al. 2010; Maldonado-Bandala et al. 2011). Biomass ash from thermal treatment contains $\mathrm{SiO}_{2}, \mathrm{Al}_{2} \mathrm{O}_{3}$, and $\mathrm{Fe}_{2} \mathrm{O}_{3}$, suggesting the possibility of exhibiting pozzolanic properties (Rajamma et al. 2009). Active silica and alumina are very useful materials that react with calcium hydroxide to produce the $\mathrm{C}-\mathrm{S}-\mathrm{H}$, which contributes to improving the strength of cement-based materials (Biricik et al. 1999). Calcination can impart pozzolanic activity to biomass ashes, such as palm oil clinker powder, wheat straw ash, sugar cane bagasse ash, and sugar cane straw ash (Cociña et al. 2013; Moraes et al. 2015; Karim et al. 2016).

The combustion temperature can influence the composition, microstructure, and pozzolanic properties of different kinds of biomass ash. Rice husk calcined at 500, 600, 700 , and $800{ }^{\circ} \mathrm{C}$ was tested for its compressive strength and analyzed using X-ray powder diffraction (XRD), and it was concluded that the optimum combustion temperature for obtaining highly reactive rice husk ash (RHA) is $600{ }^{\circ} \mathrm{C}(\mathrm{Xu}$ et al. 2012). Sugar cane straw ash (SCSA) with $20 \%$ and $30 \%$ clay content burned at 800 and $1000{ }^{\circ} \mathrm{C}$ and then reacted with lime showed that SCSA has good pozzolanic activity, comparable to that of rice husk ash (Cociña et al. 2003). The consistent results reported by Morales et al. (2009) showed that sugar cane waste ash calcined at 800 and $1000{ }^{\circ} \mathrm{C}$ have properties indicative of high pozzolanic activity. It is very interesting that identical species of biomass ash from different production areas require different calcination temperatures to yield high pozzolanic activity. Brazilian bamboo leaf ash calcined at $600{ }^{\circ} \mathrm{C}$ had a very high pozzolanic activity (Frías et al. 2012). However, Cuban bamboo leaf ash calcined at 500, 600, and $700{ }^{\circ} \mathrm{C}$ was evaluated for pozzolanic activity by using a conductometric method, and it was found that Cuban bamboo leaf ash calcined at $500{ }^{\circ} \mathrm{C}$ showed the highest pozzolanic activity (Cociña et al. 2018).

When the ash deformation temperatures of biomass ash were investigated, it was found that calcination temperatures $\geq 550{ }^{\circ} \mathrm{C}$ completely removed the organic matter from rice straw. Further, the ashes underwent significant sintering when calcined at $650{ }^{\circ} \mathrm{C}$ due to the presence of potassium chloride (Roselló et al. 2017). In addition, the ash deformation temperatures of red pine and straw were over $1100{ }^{\circ} \mathrm{C}$ (Fang and Jia 2012).

The minerals and phases containing $\mathrm{Si}$ and $\mathrm{Al}$ elements are transformed during the combustion of biomass ash. Due to the presence of totally crystalline silica in the original rice husk ash prepared at $800{ }^{\circ} \mathrm{C}$, a leaching procedure, low calcination temperature, and short calcination time were proposed to prepare more active amorphous silica from rice husk (Shen et al. 2011). The porosity of lemon grass ash and the crystallinity of the silica in the lemon grass ash increased as the calcination temperature was increased from 0 to $700{ }^{\circ} \mathrm{C}$ (Firdaus et al. 2016). Bamboo leaf fired in an open atmosphere and then heated at $600{ }^{\circ} \mathrm{C}$ for $2 \mathrm{~h}$ in a furnace is an amorphous material containing amorphous silica (Dwivedia et al. 2006). In addition, based on Vassilev et al. (2013b), fluxing and refractory behaviors of different modes of elements occur during the combustion of biomass according to the melting point (MP) of the minerals and phases containing Al elements. Elemental Al, K-Al sulphate, K-aluminosilicate, and albite appeared at 660, 690 to 800, 695 , and $1118{ }^{\circ} \mathrm{C}$ calcination temperatures, respectively. The $\mathrm{K}$ feldspar, microcline, orthoclase, and sanidine appeared at $1170{ }^{\circ} \mathrm{C}$, whereas biotite, chlorite, and muscovite appeared at $1200^{\circ} \mathrm{C}$.

Above all, the factors that influence the physical and chemical properties of the biomass ash were the calcination temperature, components of the biomass, production location, and biomass species. However, the evolution of the physical and chemical 
properties for maize stalk, and in particular maize stalk leaf ash (MSLA) in China, with increasing calcination temperature has been rarely reported. The change of the characteristics after thermal and aqueous solution treatment (water is the primary raw material in cement-based materials) must be investigated. It is essential to develop environmentally friendly and inexpensive management of maize straw ash.

In this study, the composition and microstructure of maize stalk leaf ash calcined at 500,700 , and $850{ }^{\circ} \mathrm{C}$ were investigated. The $\mathrm{pH}$ values and zeta potentials of MSLA mixed in deionized water for 0 to $2 \mathrm{~h}$ were measured. The mineralogy, Si $2 \mathrm{p}$, and Al $2 \mathrm{p}$ chemical bonds of the calcined MSLA, and water-leaching residue were investigated. This knowledge is essential for understanding the effect of calcination temperature on the characteristics of MSLA and the water-leaching properties of MSLA. These conclusions will be useful for assessing the possibility of using MSLA in cementing systems.

\section{EXPERIMENTAL}

\section{Materials}

The maize stalk leaf samples from Shanxi province China were obtained with the stems removed. The stalk leaves were washed using tap water to remove impurities, dried at $105^{\circ} \mathrm{C}$ for $24 \mathrm{~h}$ in a circulating oven, and then were crushed to a $1-\mathrm{cm}$ grain size. The crushed leaves were placed into a muffle furnace to calcine for $3 \mathrm{~h}$ at 500,700 , or $850{ }^{\circ} \mathrm{C}$. Then, the cooled MSLA was milled and filtered using a $0.074-\mathrm{mm}$ membrane filter, and the samples were characterized using a Laser particle size analyzer, X-ray photoelectron spectroscopy (XPS), scanning electron microscopy (SEM), and X-ray powder diffraction (XRD). The filtered solid samples from the three calcination temperatures were dissolved in deionized water at a liquid-to-solid $(\mathrm{L} / \mathrm{S})$ ratio of $2 / 15 \mathrm{~L} / \mathrm{g}$. The $\mathrm{pH}$ values of the solutions were tested at $15 \mathrm{~min}$ intervals for $2 \mathrm{~h}$, and the zeta potentials were measured after 30,60 , and $90 \mathrm{~min}$. The residues after leaching for 30 and $120 \mathrm{~min}$ were oven-dried at $80{ }^{\circ} \mathrm{C}$. The $\mathrm{XRD}$ and X-ray fluorescence (XRF) analyses of the dried residue were performed. Figure 1 shows the preparation process of the straw stalk leaf ash samples.

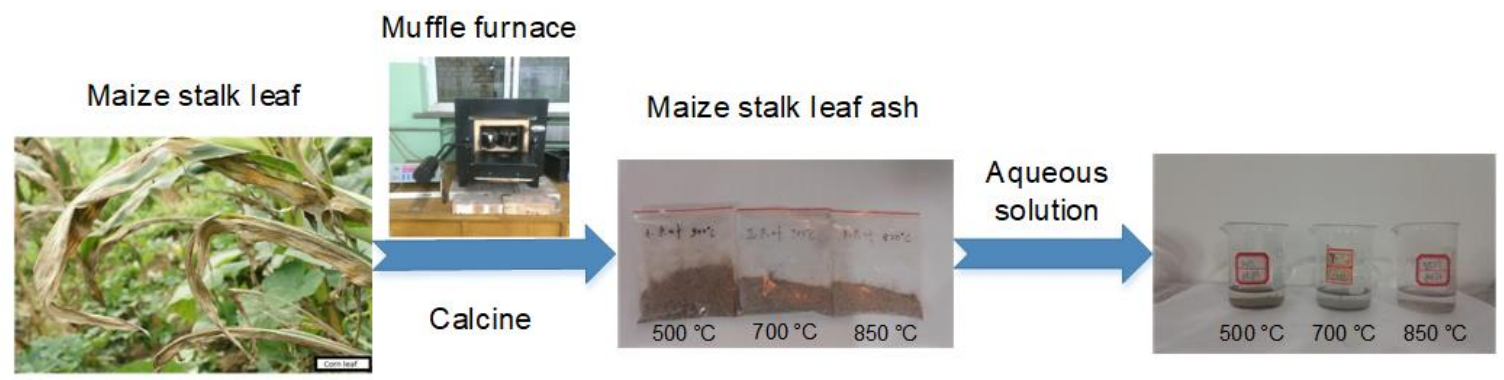

Fig. 1. Process of preparing straw stalk leaf ash samples

\section{Methods}

The grain size distribution (GSD) of MSLA is an important property, because it can affect the resultant paste consistency, chemical reactivity, and the overall hydromechanical properties. The GSD curves of the MSLA samples were determined using a Malvern Laser Mastersizer S 2000 (Malvern Instruments Inc., Worcestershire, UK), which is capable of measuring particles between 0.05 and $880 \mu \mathrm{m}$ with an accuracy of $\pm 1 \%$. 
An XPS analysis was performed using an Axis Ultra DLD instrument (Kratos, Manchester, UK) for surface characterization. The powder samples were heated for approximately $2 \mathrm{~h}$ at $80{ }^{\circ} \mathrm{C}$ in air to reduce the amount of adsorbed water. Immediately after removing them from the oven, the samples were fixed on adhesive tape and introduced into the vacuum system. Photoelectron emission was excited via a monochromatic Al Ka line with photon energy of $1486.67 \mathrm{eV}$.

The microstructure analysis of MSLA samples was performed using a JEOL JSM 6390 LV (JEOL Ltd., Tokyo, Japan) electron microscope at $25 \mathrm{kV}$. The samples were previously Au coated (SKY Technology Development Corp., Shenyang, China) to avoid charging problems.

The MSLA and MSLA residuals were characterized by X-ray powder diffractometry using an Ultima IV Rigaku diffractometer (Rigaku Corp., Tokyo, Japan) equipped with $\mathrm{Cu} \mathrm{K \alpha 1,2}(\lambda=1.54178 \AA)$ radiation with a generator voltage of $40.0 \mathrm{kV}$ and a current of $40.0 \mathrm{~mA}$. The $2 \theta$ range of $5^{\circ}$ to $90^{\circ}$ was used for all powders in continuous scan mode with a scanning step of $0.02^{\circ}$ at a rate of $10^{\circ} / \mathrm{min}$.

The main chemical composition of MSLA (in the form of oxides) was determined by XRF (ZSX Primus II; Rigaku Corp., Tokyo, Japan). The samples used for XRF testing were heated at $550{ }^{\circ} \mathrm{C}$ for $2 \mathrm{~h}$, according to GB/T 28731 (2012). The softening temperatures (ST) were measured according to GB/T 30726 (2014).

The zeta potentials in the aqueous solutions of MSLA were characterized using a microscopic electrophoresis apparatus (JS94H; Powereach Corp., Shanghai, China) with an $\mathrm{Ag}$ electrode. The measurement parameters were: particle size range of 0.5 to $20 \mu \mathrm{m}$, input $\mathrm{pH}$ range of 1.6 to 13.0 , step length of 0.1 , and switching time of $700 \mathrm{~ms}$. The $\mathrm{pH}$ values of the solutions were measured using a LEICI PHSJ-3 (INESA Scientific Instrument Co., Ltd., Shanghai, China) $\mathrm{pH}$ meter, and the criterion $\mathrm{pH}$ value was adjusted before each measurement.

\section{RESULTS AND DISCUSSION}

\section{Particle Size Distribution}

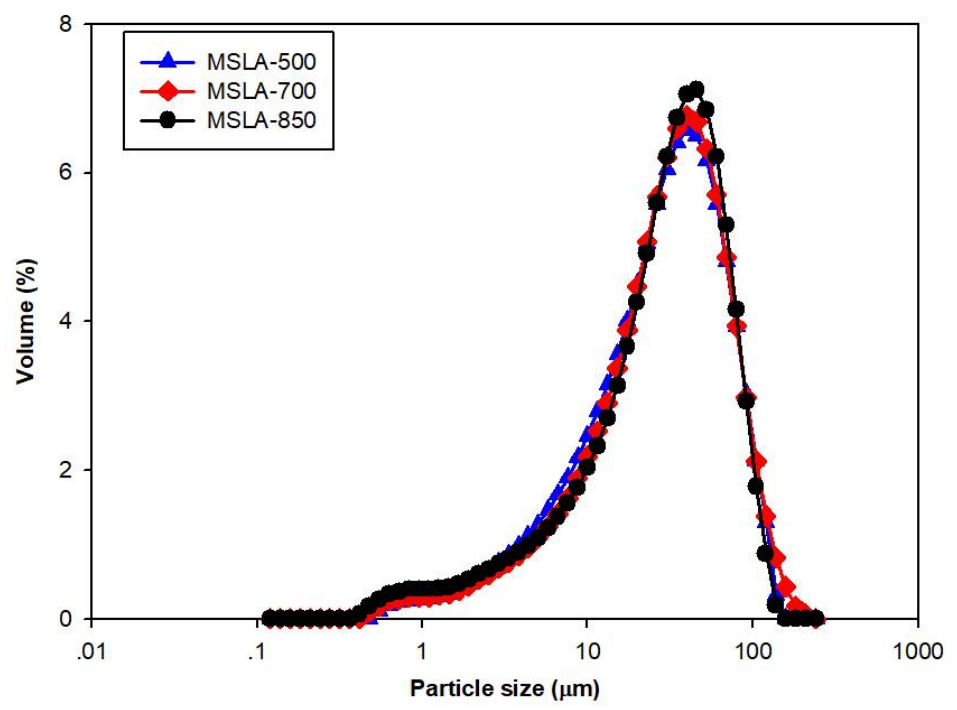

Fig. 2. Grain size distribution of MSLA calcined at 500,700 , and $850^{\circ} \mathrm{C}$ 
According to the GSD curves of the samples (0.074 mm) (Fig. 2) and Table 1, the specific surface areas slightly increased with increasing calcination temperature. The particle sizes of MSLA with different calcination temperatures were close to a continuous gradation.

\section{Chemical Composition}

As shown in Table 1, the loss on ignition increased with increasing temperature. The chemical compositions of the maize stalk ashes, shown in Table 1, varied depending on the combustion temperature. Silica, potassium oxide, magnesium oxide, and lime compounds were predominantly observed in the samples. The abundance of $\mathrm{K}$ in MSLA together with the high Si content favors the formation of alkali-rich silicates and thus decreases the ash melting temperature (Zhu et al. 2018).

Table 1. Chemical Composition of Maize Stalk Leaf Calcined at 500, 700, and $850^{\circ} \mathrm{C}$

\begin{tabular}{|c|c|c|c|}
\hline & MSLA-500 & MSLA-700 & MSLA-850 \\
\hline $\mathrm{SiO}_{2}(\%)$ & 67.02 & 72.86 & 73.53 \\
\hline $\mathrm{Al}_{2} \mathrm{O}_{3}(\%)$ & 2.15 & 2.09 & 2.64 \\
\hline $\mathrm{Fe}_{2} \mathrm{O}_{3}(\%)$ & 1.01 & 1.02 & 1.27 \\
\hline $\mathrm{CaO}(\%)$ & 6.78 & 7.72 & 7.99 \\
\hline $\mathrm{MgO}(\%)$ & 3.68 & 4.29 & 4.29 \\
\hline $\mathrm{SO}_{3}(\%)$ & 2.42 & 1.96 & 2.25 \\
\hline $\mathrm{TiO}_{2}(\%)$ & 0.13 & 0.12 & 0.16 \\
\hline $\mathrm{K}_{2} \mathrm{O}(\%)$ & 5.24 & 4.91 & 3.80 \\
\hline $\mathrm{Na}_{2} \mathrm{O}(\%)$ & 0.40 & 0.50 & 0.57 \\
\hline $\mathrm{P}_{2} \mathrm{O}_{5}(\%)$ & 0.94 & 0.97 & 1.08 \\
\hline $\mathrm{Cl}(\%)$ & 0.39 & 0.25 & ---- \\
\hline $\mathrm{CuO}(\%)$ & 0.23 & 0.21 & 0.10 \\
\hline $\mathrm{SUM}(\%)$ & 89.77 & 96.44 & 97.58 \\
\hline $\mathrm{LOI}(\%)$ & 89.41 & 90.67 & 91.48 \\
\hline $\begin{array}{c}\text { Specific Surface Area } \\
\left(m^{2} / g\right)\end{array}$ & 0.534 & 0.550 & 0.633 \\
\hline
\end{tabular}

Meanwhile, the contents of refractory species $\mathrm{Mg}, \mathrm{Ca}, \mathrm{Fe}, \mathrm{Al}, \mathrm{Si}, \mathrm{S}$, and $\mathrm{P}$ were nearly constant or slightly increased with temperature. This increase was attributed to the increase of the relative content of these elements with the release of volatile species. The increase of $\mathrm{Mg}, \mathrm{Ca}, \mathrm{P}$, and $\mathrm{S}$ contents in the ash implies that high melting temperature substances were formed (Bostrom et al. 2011). The chemical composition of MSLA is similar to that of sugarcane biomass ash (Katare and Madurwar 2017) and rice straw ash (Wang et al. 2013). The $\mathrm{SiO}_{2}, \mathrm{Al}_{2} \mathrm{O}_{3}$, and $\mathrm{Fe}_{3} \mathrm{O}_{4}$ are the main active pozzolanic substances. The Si content was remarkably higher than the $\mathrm{Al}$ and Fe contents. Thus, Si was the major pozzolanic substance in the cement-based-MSLA system.

\section{pH Value}

When the calcined MSLA samples were dissolved in deionized water within 0 to $120 \mathrm{~min}$, the order of $\mathrm{pH}$ values was MSLA-500 > MSLA-700 > MSLA-850 at all dissolving times (Fig. 3). This was due to the higher concentration of $\mathrm{OH}^{-}$in the MSLA500 aqueous solution. The aqueous solutions of the MSLA samples were alkaline due to the high $\mathrm{K}_{2} \mathrm{O}$ and $\mathrm{CaO}$ contents of MSLA (Font et al. 2017). The MSLA could be used as an alkali source in alkali-activated materials. 


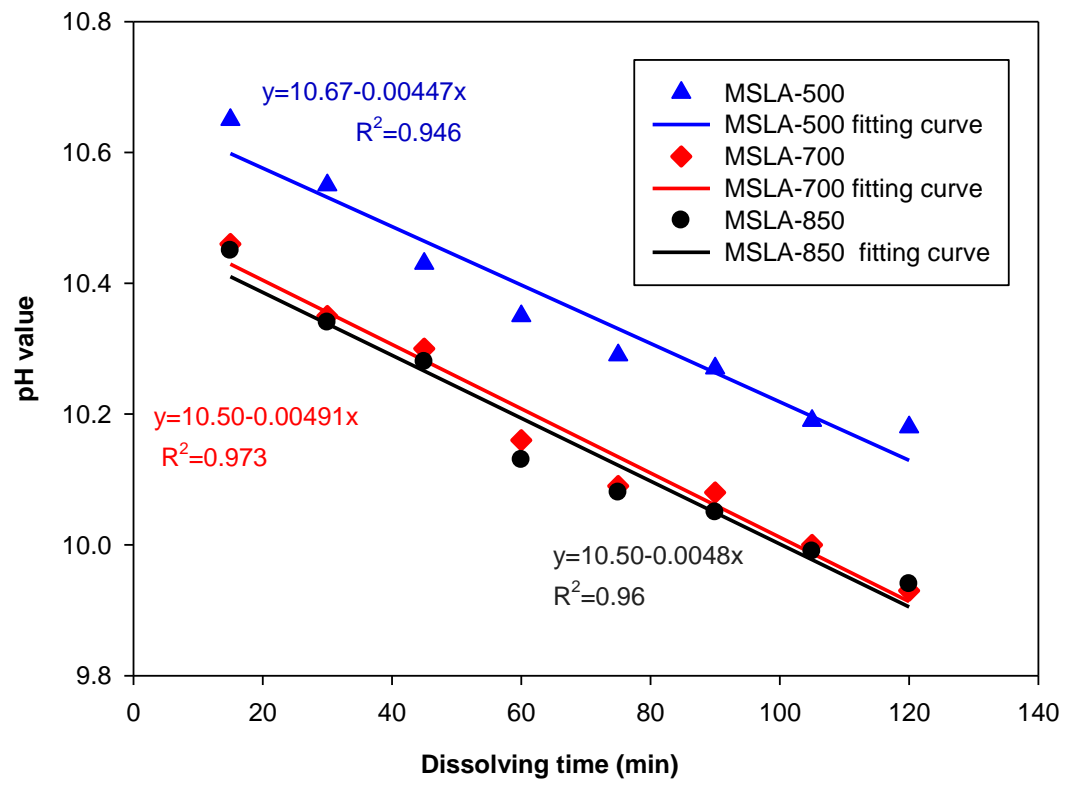

Fig. 3. The relationship between $\mathrm{pH}$ value and dissolving time of MSLA-500, MSLA-700, and MSLA-850 mixing in the aqueous solution

The $\mathrm{pH}$ value decreased with increasing dissolving time, due to the consumption of $\mathrm{OH}^{-}$ions that participate in the chemical reactions producing more $-\mathrm{OH}$ minerals (seen from the XRD in the MSLA residuals). The $\mathrm{pH}$ curves were fit using linear regression and yielded equations with negative slopes.

Amorphous $\mathrm{SiO}_{2}$ and $\mathrm{Al}_{2} \mathrm{O}_{3}$ might have been responsible for the decreasing $\mathrm{pH}$ of the aqueous solutions. The silicate precursors were formed in situ through dissolution of amorphous silica particles by the alkaline solutions (Simonsen et al. 2009a). The dissolution of the amorphous silica in alkaline conditions can produce $\mathrm{H}_{4} \mathrm{SiO}_{4}, \mathrm{H}_{3} \mathrm{SiO}_{4}$, and $\mathrm{H}_{2} \mathrm{SiO}_{4}{ }^{2-}$. These reactions suggest that $\mathrm{H}_{2} \mathrm{O}$ and $\mathrm{OH}^{-}$are consumed during the dissolution process, resulting in a decrease in $\mathrm{pH}$ that also was observed experimentally (Simonsen et al. 2009b). In contrast, the amorphous $\mathrm{Al}_{2} \mathrm{O}_{3}$ reacted with $\mathrm{OH}^{-}$to form amorphous $\mathrm{Al}(\mathrm{OH})_{3}$ in the alkali aqueous solution, which also leads to the decrease in the $\mathrm{pH}$ values of the aqueous solutions (Dijkstra et al. 2006).

\section{Zeta Potential}

To see the role of surface charge on repulsion, the zeta potential of the MSLA was calculated and found to have a negative value (Table 2). This result indicated that the surfaces of the MSLA particles had moderate negative charges. The electronegative surface of MSLA might have been due to the presence of minerals and unburnt biomolecules in the MSLA.

Table 2. Zeta Potential (mV) of MSLA Calcined at 500,700 , and $850^{\circ} \mathrm{C}$ Dissolving in Aqueous Solution for 30,60, and 90 min

\begin{tabular}{|c|c|c|c|}
\hline Calcination & \multicolumn{3}{|c|}{ Dissolving Time (min) / Zeta Potential (eV) } \\
\cline { 2 - 4 } Temperature $\left({ }^{\circ} \mathrm{C}\right)$ & 30 & 60 & 90 \\
\hline 500 & -1.98 & -1.13 & -5.23 \\
\hline 700 & -2.26 & -2.24 & -11.58 \\
\hline 850 & -2.27 & -2.25 & -19.17 \\
\hline
\end{tabular}




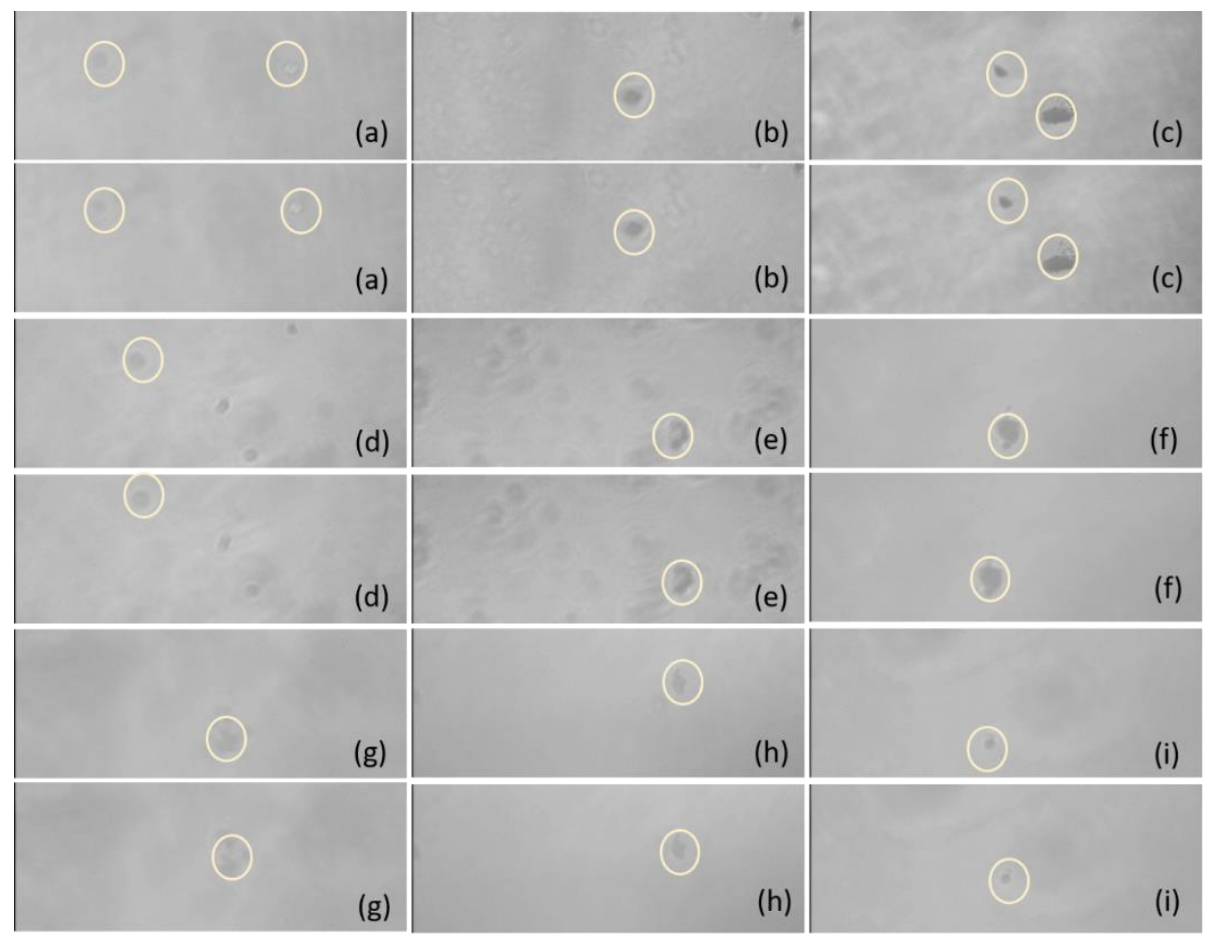

Fig. 5. The movement of MSLA-500 particles in an electric field after (a) $30 \mathrm{~min}$, (b) $60 \mathrm{~min}$, and (c) 90 min of dissolving time. The movement of MSLA-700 particles in an electric field after (d) 30 min, (e) $60 \mathrm{~min}$, and (f) 90 min of dissolving time. The movement of MSLA-850 particles in an electric field after (g) $30 \mathrm{~min}$, (h) $60 \mathrm{~min}$, and (i) $90 \mathrm{~min}$ of dissolving time. The two pictures for each letter to show the MSLA particle movement for the two opposite direction currents of the electric field in the aqueous solution.

An electronegative surface of MSLA can be more beneficial for repulsion of the anions of cement. It was found that the zeta potentials first slightly decreased and then sharply increased with increased dissolving time, changing into a " $\mathrm{V}$ " shape. Moreover, the zeta potential of the $850{ }^{\circ} \mathrm{C}$ sample showed a higher value and higher rise rate than those of the samples calcined at the other temperatures. When the alkali metal ions dissolved in the aqueous solutions, alkali metal ions (e.g., potassium, sodium, and calcium) neutralized the negative charges and reacted with the $\mathrm{OH}^{-}$at the surface of the MSLA producing new minerals that wrap the particles, which led to compression of the electric double layer due to electrostatic interactions. This may explain the decline of the zeta potential in the interval of 30 to $60 \mathrm{~min}$. As the dissolving time increased, the surfaces of the particles constantly absorbed $\mathrm{OH}^{-}$from the aqueous solution, which added to the negative charge. This may explain the ascent of the zeta potential in the interval of 60 to 90 min (Moghal and Sivapullaiah 2012). Figure 5 shows the MSLA particles with different calcination temperatures and dissolving times moving in the electric field. Larger values of the zeta potential led to a larger relative distance traversed by the MSLA particles in the electric field.

Therefore, this suggests that adding the MSLA-850 in the cement system improved the flowability of the slurry for the cemented paste backfill (CPB) or the cemented coal gangue backfill (CGB) due to the repulsion of the MSLA particles by the identically charged surfaces of the cement particles, preventing flocculation (Givi et al. 2010). 


\section{SEM}

As can be seen in Fig. 6a, the morphology of the MSLA after calcination at $500{ }^{\circ} \mathrm{C}$ showed a tubular porous aggregate shape. This characteristic was due to the removal of the hemicellulose, cellulose, and lignin after calcination at $500{ }^{\circ} \mathrm{C}$.
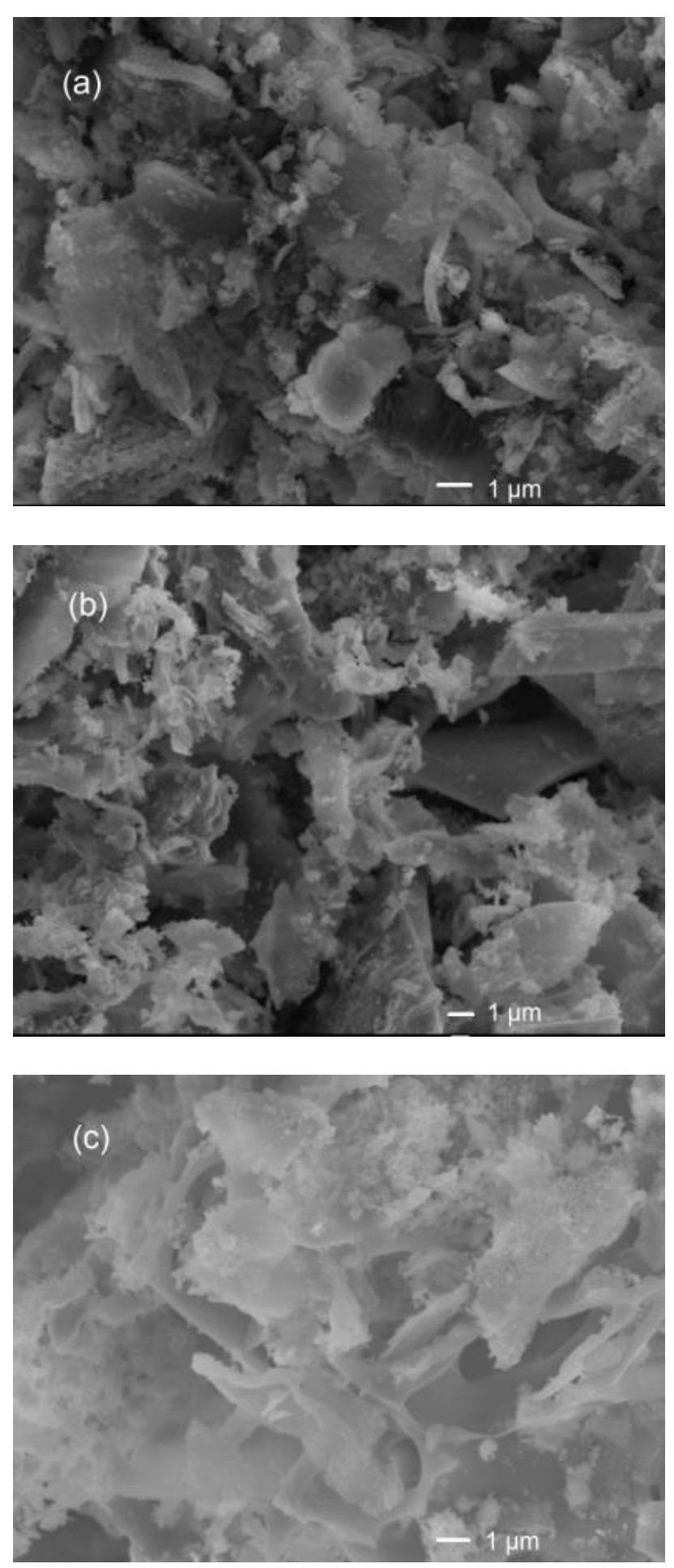

Fig. 6. SEM images of MSLA with different calcination temperatures: (a) $500^{\circ} \mathrm{C}$, (b) $700{ }^{\circ} \mathrm{C}$, and $850^{\circ} \mathrm{C}$ 
The irregularly shaped particles were distributed on the surface of MSLA-700 (shown in Fig. 6b). The SEM images obtained confirm that particle aggregation occurred when the samples were thermally treated. Increasing the treatment temperature promoted the emergence of a more intact structure. Compared to MSLA thermally treated at temperatures below $700{ }^{\circ} \mathrm{C}$, larger numbers of agglomerated particles and polyporous structures were observed for the MSLA treated at $850^{\circ} \mathrm{C}$ (Fig. 6c).

\section{XRD}

Silica has three main polymorphous crystalline forms, quartz, tridymite, and cristobalite, all with relatively complex structures and atoms that are not closely packed (Callister and Rethwisch 2010).
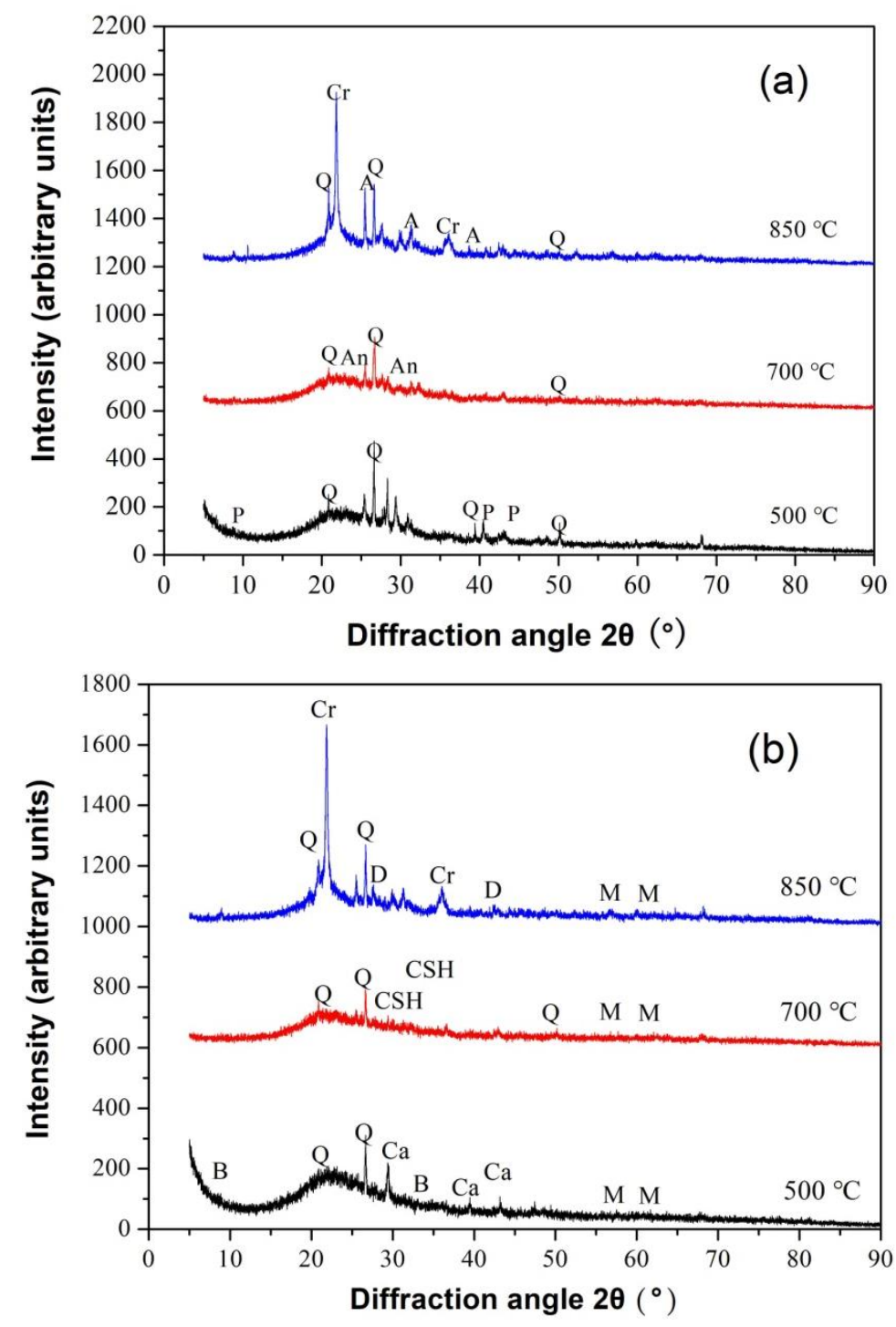

Fig. 7. XRD patterns for MSLA-500, MSLA-700, and MSLA-850 for (a) no dissolving and (b) dissolving for 120 min; Key: $\mathrm{Q}=$ Quartz $\mathrm{SiO}_{2} ; \mathrm{An}=$ Anorthite $\mathrm{Ca}\left(\mathrm{Al}_{2} \mathrm{Si}_{2} \mathrm{O}_{8}\right) ; \mathrm{A}=$ Anhydrite $\mathrm{CaSO}_{4} ; \mathrm{Cr}=$ Cristobalite $\mathrm{SiO}_{2} ; \mathrm{Ca}=$ Calcium Carbonate $\mathrm{CaCO}_{3} ; \mathrm{B}=$ Biotite $\mathrm{KMg}_{3} \mathrm{AlSi}_{3} \mathrm{O}_{10} \mathrm{OHF} ; \mathrm{M}$ $=$ Muscovite $\mathrm{KAl}_{2.20}\left(\mathrm{Si}_{3} \mathrm{Al}\right)_{0.975} \mathrm{O}_{10}\left((\mathrm{OH})_{1.72} \mathrm{O}_{0.28}\right) ; \mathrm{CSH}=$ Calcium Silicate Hydrate $\mathrm{Ca}_{1.5} \mathrm{SiO}_{3.5}$. $\mathrm{XH}_{2} \mathrm{O}$; and $\mathrm{D}=$ Diopside $\mathrm{CaMgSi}_{2} \mathrm{O}_{6}$ 
The diffractogram peaks obtained for the thermally treated maize stalk leaves show that the ash type has the quartz silica form (Fig. 7a), whose peak is marked in the diffractograms for the MSLA samples. The peak of the other silica form, cristobalite, was observed only in the $850{ }^{\circ} \mathrm{C}$ sample, which is much less than the theoretical temperature of thermal transformations of pure silica into cristobalite (Pagliari et al. 2013). The reason is that MSLA contains, in addition to $\mathrm{SiO}_{2}$, compounds with high alkali metal levels and contaminants that may affect the melting point and crystallization (Soltani et al. 2015). Furthermore, the amorphous silica in the MSLA was inclined to transform into cristobalite rather than tridymite, mainly due to the existence of crystal nuclei of cristobalite formed from the opal-cristobalite phase transition (Zheng et al. 2018). A previous study also showed that the silica phase transformation in RHA begins at 600 and $800{ }^{\circ} \mathrm{C}$, and the cristobalite phase begins at $800^{\circ} \mathrm{C}$ (Kapur 1985; Fernandes et al. 2017). However, it should be mentioned that a portion of the ash components was probably present in an amorphous phase, which could not be identified by XRD analysis.

In addition, muscovite was found in the MSLA residual (Fig. 7b), because alkali hydroxides mostly dominated at high $\mathrm{pH}$ values in the aqueous solution (from $\mathrm{pH}$ test results). The surface of MSLA was negatively charged (from the zeta potential results); metals are adsorbed in the MSLA with a strong tendency to form chemical bonds between the metal groups and the oxide surface (Liu et al. 2018).

\section{XPS}

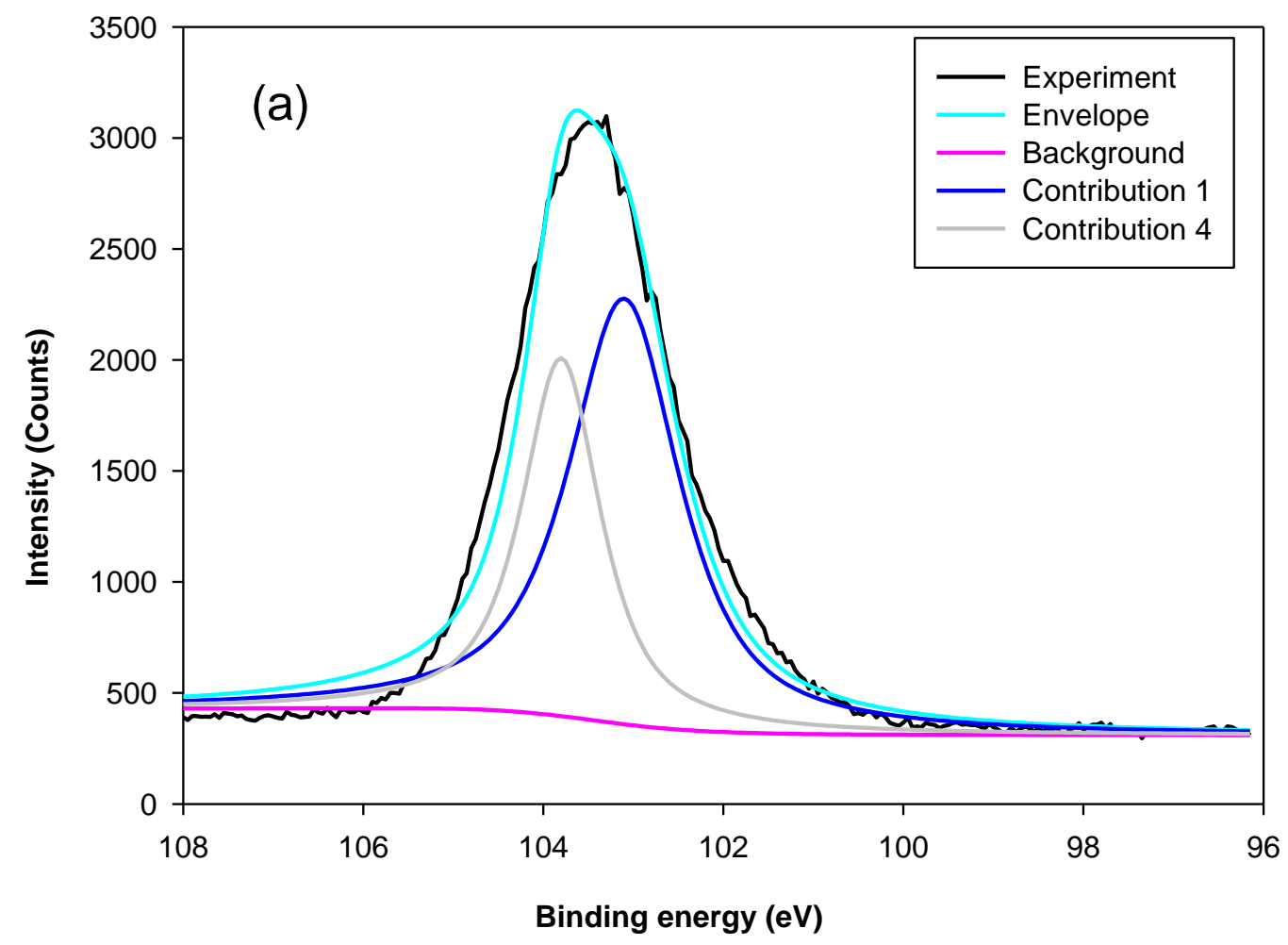



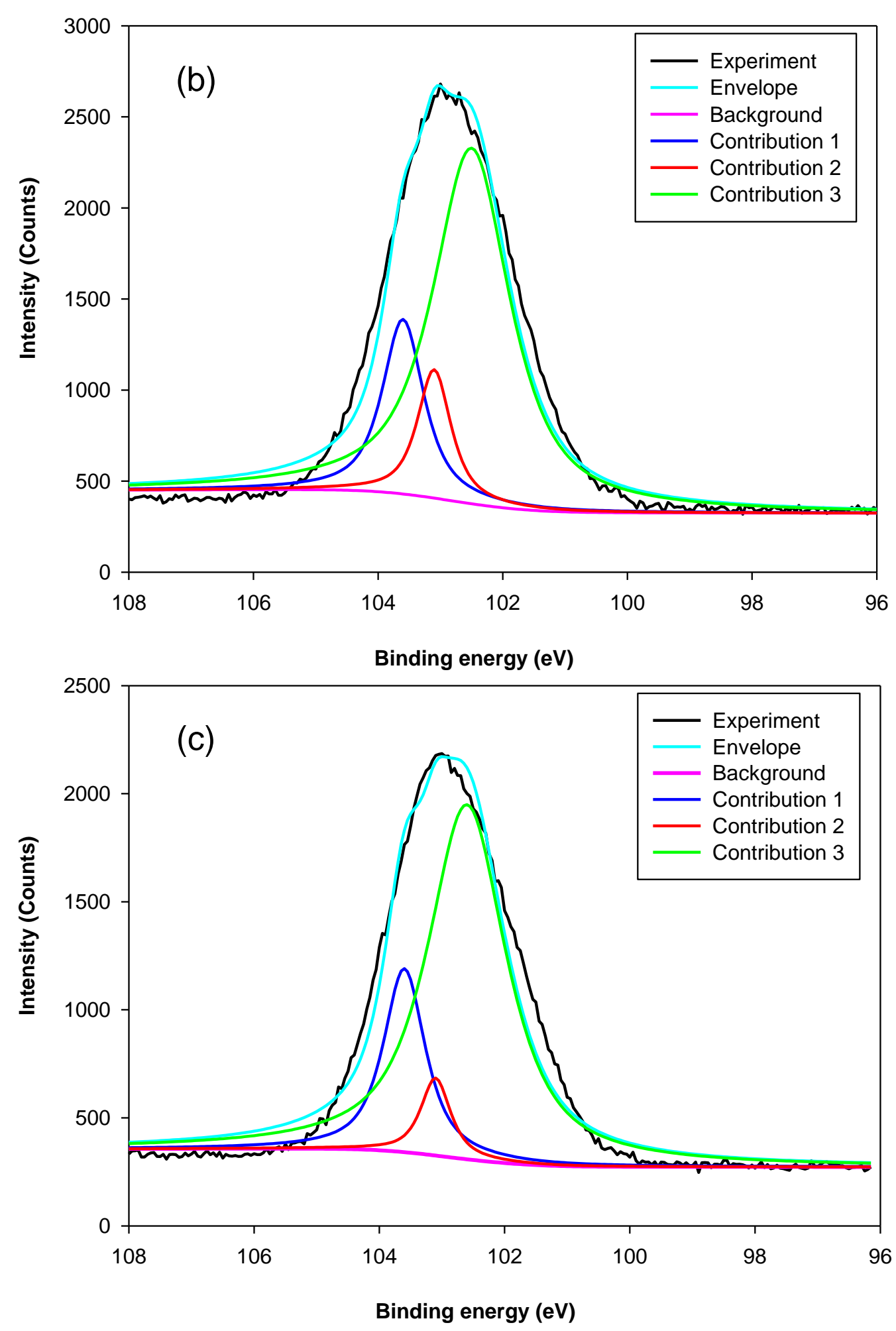

Fig. 8. The typical Si $2 p$ XPS survey spectra for MSLA at (a) 500 , (b) 700 , and (c) $850{ }^{\circ} \mathrm{C}$ 

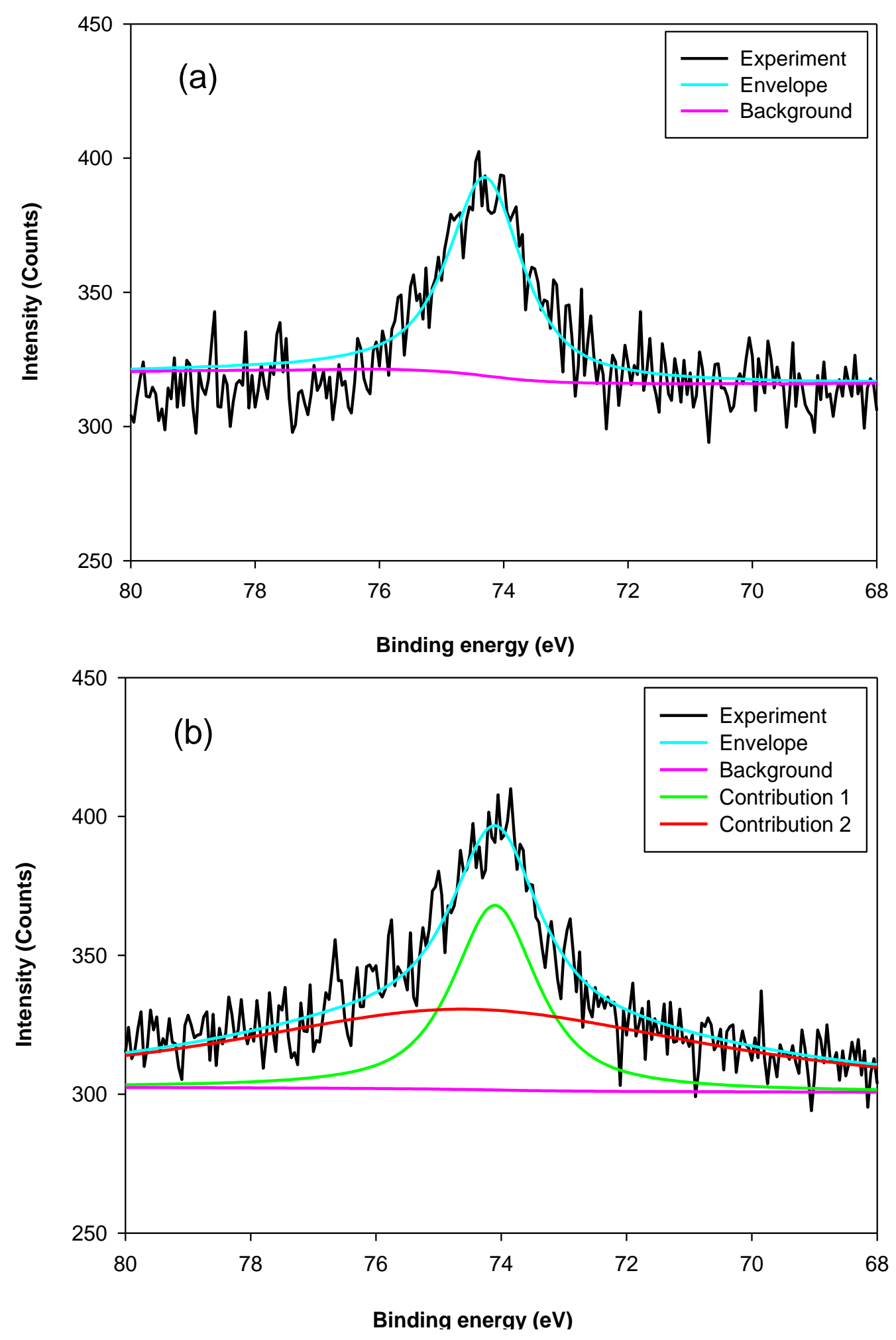


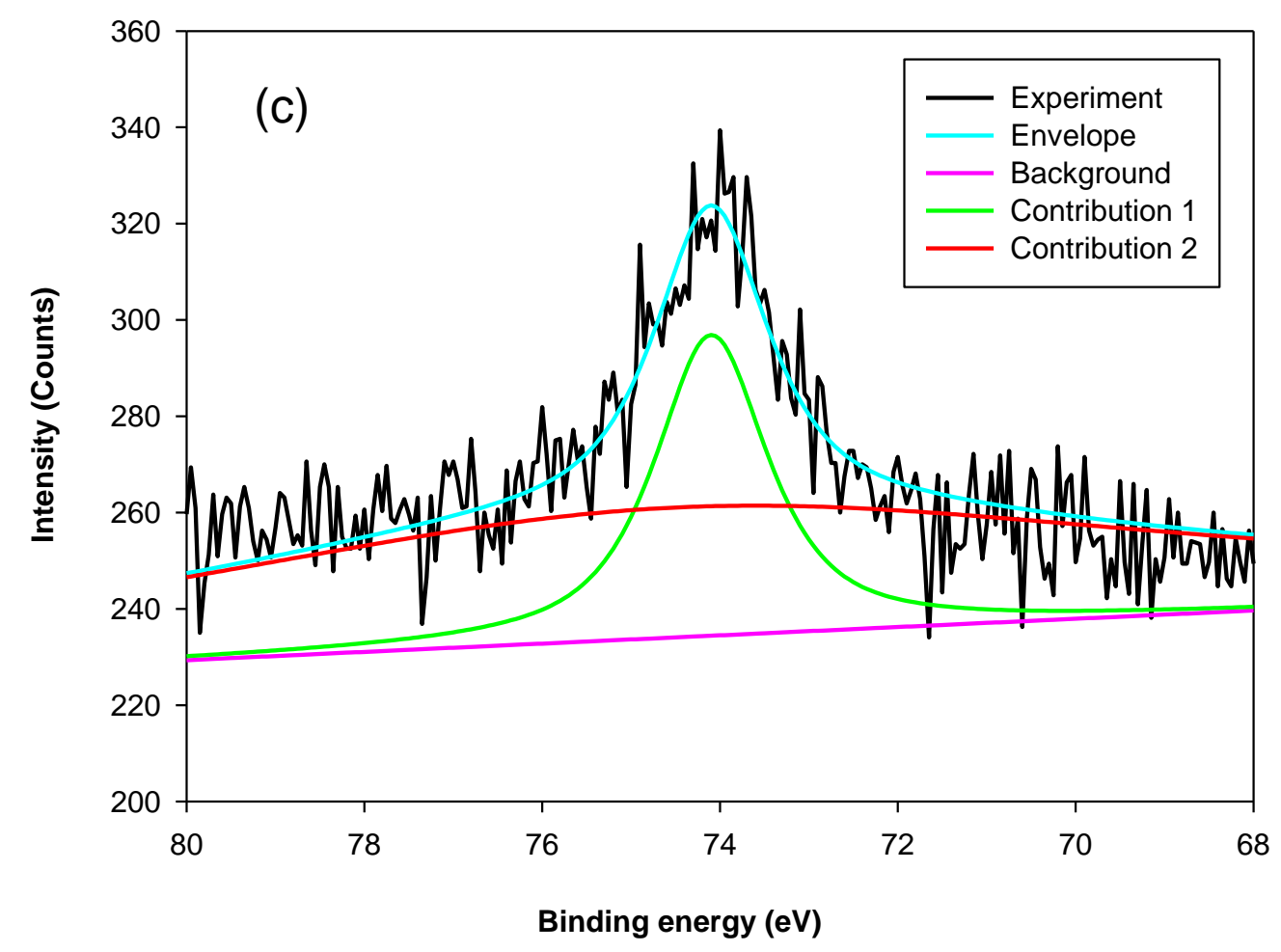

Fig. 9. The typical Al 2p XPS survey spectra for MSLA at (a) 500, (b) 700 , and (c) $850^{\circ} \mathrm{C}$

Table 3. Fitting Results of the Si $2 p$ and Al $2 p$ Lines Taken From MSLA-500, MSLA-700, and MSLA-850

\begin{tabular}{|c|c|c|c|c|c|c|}
\hline \multirow{2}{*}{ Sample } & \multicolumn{5}{|c|}{ Si 2p $3 / 2(\mathrm{eV} / \%)$} & \multicolumn{2}{c|}{ Al 2p 3/2 (eV/ \%) } \\
\cline { 2 - 7 } & Contrib. 1 & Contrib. 2 & Contrib. 3 & Contrib. 4 & Contrib. 1 & Contrib. 2 \\
\hline \multirow{2}{*}{ MSA-500 } & ---- & $103.1 /$ & ---- & $103.8 /$ & 74.3 & --- \\
& & $62.8 \%$ & & $37.2 \%$ & & \\
\hline \multirow{2}{*}{ MSA-700 } & $103.6 /$ & $103.1 /$ & $102.6 /$ & -- & $74.1 /$ & $74.5 /$ \\
& $18.6 \%$ & $11.1 \%$ & $70.3 \%$ & -- & $29.0 \%$ & $71.0 \%$ \\
\hline \multirow{2}{*}{ MSA-850 } & $103.6 /$ & $103.1 /$ & $102.6 /$ & ---- & $74.1 /$ & $74.5 /$ \\
& $20.3 \%$ & $6.1 \%$ & $73.6 \%$ & & $79.3 \%$ & $20.7 \%$ \\
\hline
\end{tabular}



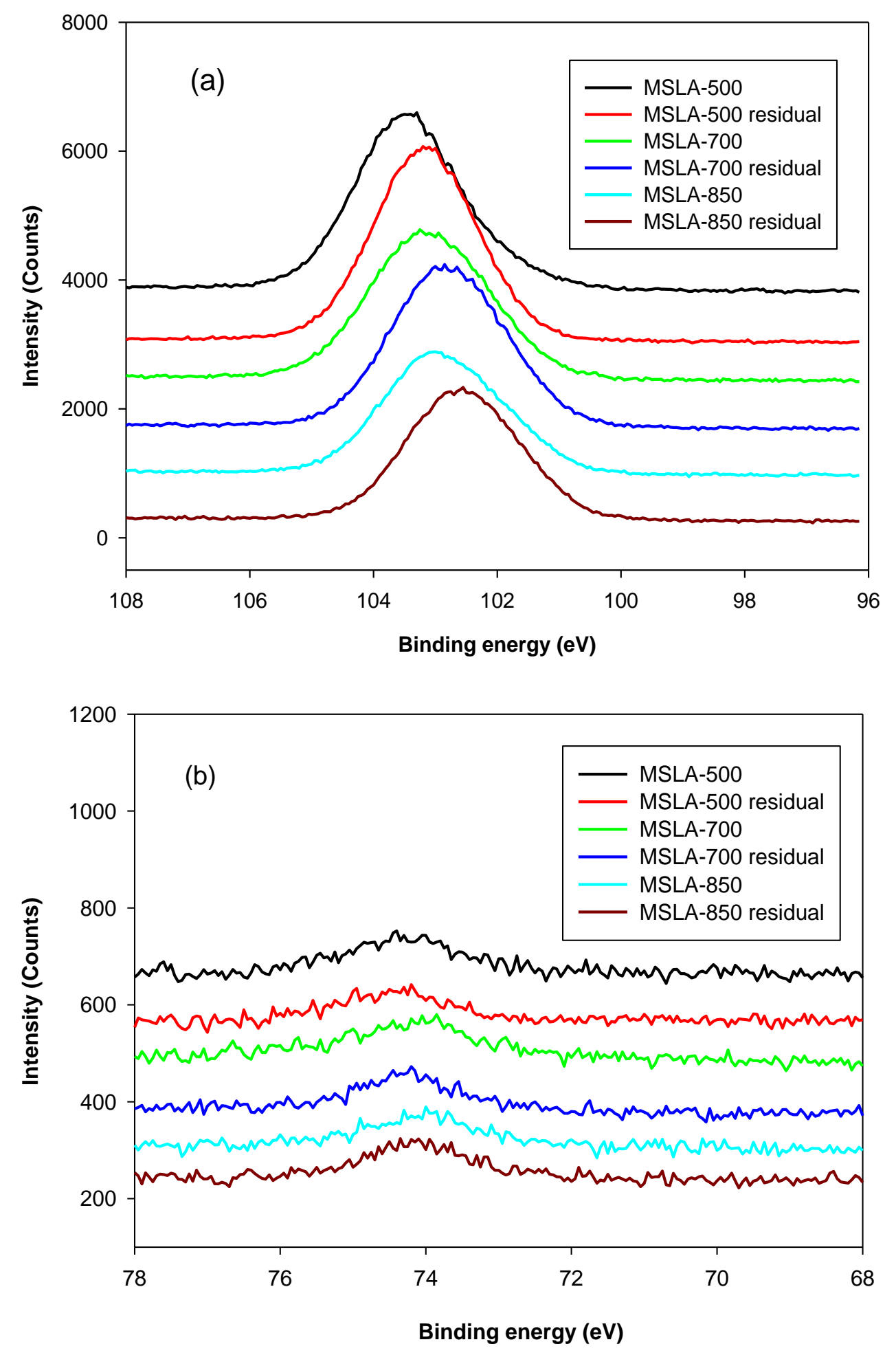

Fig. 10. (a) Si $2 p$ and (b) Al $2 p$ line shifts of the MSLA calcined at 500,700 , and $850^{\circ} \mathrm{C}$ after mixing in aqueous solution for $120 \mathrm{~min}$

The instrument used for XPS is widely applicable for probing the surface chemical composition and atomic structure of biomass ash.The fit results for Si $2 \mathrm{p}$ and $\mathrm{Al} 2 \mathrm{p}$ lines, shown in Table 3, give detailed insight into the MSLA and residual structure. Figures 8 
and 9 show the fit curves of the Si $2 p$ and Al 2p lines obtained for MSLA with different calcination temperatures, respectively. The Si 2p lines in MSLA-500 were resolved into two contributions. It should be noted that the position of this line depended on the number of sialate bonds. For instance, for pure siloxo Si-O-Si bonds, the position of Si 2 $\mathrm{p}_{3 / 2}$ was as high as $103.8 \mathrm{eV}$ (Paparazzo et al. 1992). The second contribution of the $\mathrm{Si} 2 \mathrm{p}_{3 / 2}$ line was situated at approximately $103.1 \mathrm{eV}$, corresponding to quartz. However, the position of the Si 2p line of MSLA-700 and MSLA-850 located at 103.8 eV disappeared, and at least three contributions were expected: one at approximately $103.6 \mathrm{eV}$ attributed to Si-O-Si bonds, one at approximately $103.1 \mathrm{eV}$ attributed to quartz (and cristobalite in MSLA-850), and one related to Si-OX bonds, which was as high as $102.6 \mathrm{eV}$ (Kljajević et al. 2017). As the calcination temperature increased to $850{ }^{\circ} \mathrm{C}$, the relative content of Si-OX bonds increased. It can be concluded that annealing at $700{ }^{\circ} \mathrm{C}$ resulted in the destruction of some $\mathrm{Si}-\mathrm{O}-\mathrm{Si}$ groups and the formation of another silicon compound; a possible candidate is anorthite, which corresponds to the position of peak 3. Additionally, anorthite was detected by XRD in MSLA-700.

When the MSLA dissolved in the aqueous solution, the binding energies of Si $2 p$ shifted to a lower position (shown in Fig. 10a) because of the formation of surface site $>$ $\mathrm{SiO}^{-}$(deprotonated surface sites) in the alkaline solutions. The higher amount of silicon released from cristobalite compared to that from quartz was due to the crucial effect of structural defects associated with oxygen vacancies with positive charges.

Under alkaline conditions, the surface silanols interacted with $\mathrm{OH}^{-}$to form neutral, positive, or negative surface species via deprotonation calculated by Eq. 1 (Zhu et al. 2017),

$$
>\mathrm{SiOH}+\mathrm{OH}^{-}=>\mathrm{SiO}^{-}+\mathrm{H}_{2} \mathrm{O}
$$

where $>\mathrm{SiOH}$ denotes the deprotonated surface sites. The characteristics of the surface sites could remarkably affect the solubility and reaction mechanisms of the silica minerals (Gratz and Bird 1993).

For the Al 2p line of MSLA-500, the only peak (at approximately $74.3 \mathrm{eV}$ ) was related to octahedral-coordinated bonds fit to $\mathrm{Al} 2 \mathrm{p}_{3 / 2}$. For MSLA-700, the Al 2p $3 / 2$ was resolved into two contributions. The first peak was related to an octahedral-coordinated bond, whose position shifted towards lower binding energies by roughly $0.2 \mathrm{eV}$, corresponding to the $\mathrm{Al} 2 \mathrm{p}_{3 / 2}$ lines of MSLA-700. The second peak was related to tetrahedral-coordinated bonds, situated at approximately $74.5 \mathrm{eV}$. However, the relative content of $\mathrm{Al} 2 \mathrm{p}_{3 / 2}$ for the octahedral-coordinated bond sharply increased as the calcination temperature increased. The electronic environment with the octahedral-coordinated $\mathrm{Al}$ ion was more polarizable than that with the tetrahedral-coordinated Al ion. When the MSLA was dissolved in an aqueous solution, the binding energy of the Al $2 p$ peak remarkably increased (Fig. 10b). This is an Al mineral structural dissimilarity between the MSLA and MSLA residual, caused by a change in the electronic and chemical environment (Black et al. 2003; Li et al. 2008). The Si 2p and Al 2p bond transformation behavior implied that the MSLA could react with lime to produce C-S-H.

\section{CONCLUSIONS}

1. The particle size of maize stalk leaf ash (MSLA) was close to a continuous gradation. Silica was the predominant component observed in MSLA. The order of the $\mathrm{pH}$ values 
was MSLA-500 > MSLA-700 > MSLA-850 for all dissolving times. The $\mathrm{pH}$ values gradually decreased with increasing dissolving time, and there was a linear relationship between $\mathrm{pH}$ and dissolving time.

2. The zeta potentials first slightly decreased and then remarkably increased with increasing dissolving time, changing into a " $\mathrm{V}$ "' shape. The zeta potential of the 850 ${ }^{\circ} \mathrm{C}$ sample had the largest value at all dissolving times. The morphology of the MSLA after calcination at $500{ }^{\circ} \mathrm{C}$ had a tubular porous aggregate shape. The crystallinity degree increased with increasing calcination temperature.

3. Quartz was identified in the MSLA at the different calcination temperatures. Another polymorphous crystalline form of silica, cristobalite, only appeared in the $850{ }^{\circ} \mathrm{C}$ sample, when MSLA was dissolved in an aqueous solution. Muscovite was found in the MSLA residuals due to chemical reactions of $\mathrm{OH}$ - and alkali metal. The binding energies of Si 2p and Al 2p shifted after thermal and aqueous solution treatment of the MSLA. In conclusion, the optimum calcination temperature for MSLA used in cementing systems is still tested on the pozzolanic characteristic.

\section{ACKNOWLEDGEMENTS}

This work was supported by the Joint Research Fund under a cooperative agreement between the NSFC and Funds for Coal-Based Low-Carbon Technology of Shanxi (No. U1710258); the National Natural Science Foundation of China (Nos. 51574172 and 51804208); Shanxi Province Applied Basic Research Foundation for Youths (No. 201601D021089); the Key Technologies Research and Development Coal-Based Program of Shanxi Province (MQ2014-12); the Research Fund of The State Key Laboratory of Coal Resources and Safe Mining, CUMT(SKLCRSM18KF016); and the China Postdoctoral Science Foundation (2018M632423).

\section{REFERENCES CITED}

Biricik, H., AkÖz, F., Berktay, I., and Tulgar, A. N. (1999). "Study of pozzolanic properties of wheat straw ash," Cement and Concrete Research29(5), 637-643. DOI: 10.1016/S0008-8846(98)00249-X

Black, L., Garbev, K., Stemmermann, P., Hallam, K. R., and Allen, G. C. (2003). "Characterisation of crystalline C-S-H phases by X-ray photoelectron spectroscopy," Cement and Concrete Research 33(6), 899-911. DOI: 10.1016/S00088846(02)01089-X

Bostrom, D., Skoglund, N., Grimm, A., Boman, C., Ohman, M., Brostrom, M., and Backman, R. (2011). "Ash transformation chemistry during combustion of biomass," Energy Fuels26(1), 85-93. DOI: 10.1021/ef201205b

Callister, W. D., and Rethwisch, D. G. (2010). Materials Science and Engineering: An Introduction, Eighth Ed., John Wiley \& Sons, New York, New York.

Cociña, E. V., Frías, M., Hernández-Ruiz, J., and Savastano, H. (2013). "Pozzolanic behaviour of a bagasse ash from the boiler of a Cuban sugar factory," Advances in Cement Research 25(3), 136-142. DOI: 10.1680/adcr.11.00066 
Cociña, E. V., Savastano, H., Rodier, L., Lefran, M., and Frías, M. (2018). "Pozzolanic characterization of Cuban bamboo leaf ash: Calcining temperature and kinetic parameters," Waste and Biomass Valorization 9(4), 691-699.DOI: 10.1007/s12649016-9741-8

Cociña, E. V., Valencia-Morales, E., González-Rodríguez, R., and Hernández-Ruíz, J. (2003). "Kinetics of the pozzolanic reaction between lime and sugar cane straw ash by electrical conductivity measurement: A kinetic-diffusive model," Cement and Concrete Research 33(4), 517-524. DOI: 10.1016/S0008-8846(02)00998-5

Dijkstra, J. J., Van Der Sloot, H. A., and Comans, R. N. (2006). "The leaching of major and trace elements from MSWI bottom ash as a function of $\mathrm{pH}$ and time," Applied Geochemistry 21(2), 335-351. DOI:10.1016/j.apgeochem.2005.11.003

Dwivedi, V. N., Singh, N. P., Dasa, S. S., and Singh, N. B. (2006). "A new pozzolanic material for cement industry: Bamboo leaf ash," International Journal of Physical Sciences 1(3), 106-111.

Fang, X., and Jia, L. (2012). "Experimental study on ash fusion characteristics of biomass," Bioresource Technology104, 769-774. DOI: 10.1016/j.biortech.2011.11.055

Fernandes, I. J., Sánchez, F. A. L., Jurado, J. R., Kieling, A. G., Rocha, T. L. A. C., Moraes, C. A. M., and Sousa, V. C. (2017). "Physical, chemical and electric characterization of thermally treated rice husk ash and its potential application as ceramic raw material," Advanced Powder Technology 28(4), 1228-1236. DOI: 10.1016/j.apt.2017.02.009

Firdaus, M. Y. N., Osman, H., Metselaar, H. S., and Rozyanty, A. R. (2016). "Preparation and characterization of active $\mathrm{SiO}_{2}$ from Cymbopogon citratus ash calcined at different temperature," BioResources 11(1), 2839-2849. DOI: 10.15376/biores.11.1.2839-2849

Font, A., Soriano, L., Moraes, J., Tashima, M. M., Monzó, J., Borrachero, M. V., and Pay á, J. (2017). "A 100\% waste-based alkali-activated material by using olive-stone biomass ash (OBA) and blast furnace slag (BFS)," Materials Letters203, 46-49. DOI: 10.1016/j.matlet.2017.05.129

Frías, M., Savastano, H., Villar, E., De Rojas, M. I. S., and Santos, S. (2012). "Characterization and properties of blended cement matrices containing activated bamboo leaf wastes," Cement and Concrete Composites34(9), 1019-1023. DOI: 10.1016/j.cemconcomp.2012.05.005

Gratz, A. J., and Bird, P. (1993). "Quartz dissolution: Negative crystal experiments and a rate law," Geochimica et Cosmochimica Acta57(5), 965-976. DOI: 10.1016/00167037(93)90033-S

Givi, A. N., Rashid, S. A., Aziz, F. N. A., and Salleh, M. A. M. (2010). "Assessment of the effects of rice husk ash particle size on strength, water permeability and workability of binary blended concrete," Construction and Building Materials24(11), 2145-2150. DOI: 10.1016/j.conbuildmat.2010.04.045

Kapur, P. C. (1985). "Production of reactive bio-silica from the combustion of rice husk in a tube-in-basket (TiB) burner," Powder Technology 44(1), 63-67. DOI: 10.1016/0032-5910(85)85022-1

Karim, M. R., Hashim, H., and Razak, H. A. (2016). "Assessment of pozzolanic activity of palm oil clinker powder," Construction and Building Materials127, 335-343. DOI: 10.1016/j.conbuildmat.2016.10.002 
Katare, V. D., and Madurwar, M. V. (2017). "Experimental characterization of sugarcane biomass ash- A review," Construction and Building Materials 152, 1-15. DOI: 10.1016/j.conbuildmat.2017.06.142

Li, H. J., Sun, H. H., Tie, X. C., and Xiao, X. J. (2008). "A new method to evaluate the hydraulic activity of Al-Si materials," Science in China Series E: Technological Sciences 51(2), 113-120. DOI:10.1007/s11431-007-0064-7

Liu, Z., Tian, D., Hu, J., Shen, F., Long, L., Zhang, Y., Yang, G., Zeng, Y., Zhang, J., and He, J. (2018). "Functionalizing bottom ash from biomass power plant for removing methylene blue from aqueous solution," Science of The Total Environment 634, 760-768. DOI: 10.1016/j.scitotenv.2018.04.010

Kljajević, L. M., Nenadović, S. S., Nenadović, M. T., Bundaleski, N. K., Todorović, B. Ž., Pavlović, V. B., and Rakočević, Z. L. (2017). "Structural and chemical properties of thermally treated geopolymer samples," Ceramics International 43(9), 6700-6708. DOI: 10.1016/j.ceramint.2017.02.066

Maldonado-Bandala, E. E., Jiménez-Quero, V., and Olguin-Coca, F. J. (2011). "Electrochemical characterization of modified concretes with sugar cane bagasse ash," International Journal of Electrochemical Science 6(10), 4915-4926.

Moghal, A. A. B., and Sivapullaiah, P. V. (2012). "Retention characteristics of $\mathrm{Cu}^{2+}$, $\mathrm{Pb}^{2+}$, and $\mathrm{Zn}^{2+}$ from aqueous solutions by two types of low lime fly ashes,"

Toxicological \& Environmental Chemistry 94(10), 1941-1953. DOI: 10.1080/02772248.2012.732579

Moraes, J., Akasaki, J. L., Melges, J., Monzó, J., Borrachero, M. V., Soriano, L., Payá, J., and Tashima, M. M. (2015). "Assessment of sugar cane straw ash (SCSA) as pozzolanic material in blended Portland cement: Microstructural characterization of pastes and mechanical strength of mortars," Construction and Building Materials94, 670-677. DOI: 10.1016/j.conbuildmat.2015.07.108

Morales, E. V., Cociña, E. V., Frías, M., Santos, S. F., and Savastano, Jr., H. (2009). "Effects of calcining conditions on the microstructure of sugar cane waste ashes (SCWA): Influence in the pozzolanic activation," Cement and Concrete Composites31(1), 22-28. DOI: 10.1016/j.cemconcomp.2008.10.004

Pagliari, L., Dapiaggi, M., Pavese, A., and Francescon, F. (2013). "A kinetic study of the quartz-cristobalite phase transition," Journal of the European Ceramic Society 33(1516), 3403-3410. DOI: 10.1016/j.jeurceramsoc.2013.06.014

Paparazzo, E., Fanfoni, M., Severini, E., and Priori, S. (1992). "Evidence of Si-OH species at the surface of aged silica," Journal of Vacuum Science \& Technology A: Vacuum Surfaces \& Films10(4), 2892-2896. DOI: 10.1116/1.577726

Rajamma, R., Ball, R. J., Tarelho, L. A., Allen, G. C., Labrincha, J. A., and Ferreira, V. M. (2009). "Characterisation and use of biomass fly ash in cement-based materials," Journal of Hazardous Materials172(2-3), 1049-1060. DOI: 10.1016/j.jhazmat.2009.07.109

Roselló, J., Soriano, L., Santamarina, M. P., Akasaki, J. L., Monzó, J., and Payá, J. (2017). "Rice straw ash: A potential pozzolanic supplementary material for cementing systems," Industrial Crops and Products103, 39-50. DOI: 10.1016/j.indcrop.2017.03.030

Shen, J., Liu, X., Zhu, S., Zhang, H., and Tan, J. (2011). "Effects of calcination parameters on the silica phase of original and leached rice husk ash," Materials Letters65(8), 1179-1183. DOI: 10.1016/j.matlet.2011.01.034 
Simonsen, M. E., Sønderby, C., Li, Z., and Søgaard, E. G. (2009b). "XPS and FT-IR investigation of silicate polymers," Journal of Materials Science 44(8), 2079-2088. DOI: $10.1007 / \mathrm{s} 10853-009-3270-9$

Simonsen, M. E., Sønderby, C., and Søgaard, E. G. (2009a). "Synthesis and characterization of silicate polymers," Journal of Sol-Gel Science and Technology 50(3), 372-382. DOI: 10.1007/s10971-009-1907-4

Soltani, N., Bahrami, A., Pech-Canul, M. I., and González, L. A. (2015). "Review on the physicochemical treatments of rice husk for production of advanced materials," Chemical Engineering Journal 264, 899-935. DOI: 10.1016/j.cej.2014.11.056

Vassilev, S. V., Baxter, D., Andersen, L. K., and Vassileva, C. G. (2013a). "An overview of the composition and application of biomass ash. Part 1. Phase-mineral and chemical composition and classification," Fuel 105, 40-76. DOI: 10.1016/j.fuel.2012.09.041

Vassilev, S. V., Baxter, D., and Vassileva, C. G. (2013b). "An overview of the behaviour of biomass during combustion: Part I. Phase-mineral transformations of organic and inorganic matter," Fuel 112, 391-449. DOI: 10.1016/j.fuel.2013.05.043

Wang, Y., Hu, Y., Zhao, X., Wang, S., and Xing, G. (2013). "Comparisons of biochar properties from wood material and crop residues at different temperatures and residence times," Energy \& Fuels 27(10), 5890-5899. DOI: 10.1021/ef400972z

Xiong, S., Ohman, M., Zhang, Y., and Lestander, T. R. (2010). "Corn stalk ash composition and its melting (slagging) behavior during combustion," Energy \& Fuels24(9), 4866-4871. DOI: 10.1021/ef1005995

$\mathrm{Xu}, \mathrm{W}$. , Lo, T. Y., and Memon, S. A. (2012). "Microstructure and reactivity of rich husk ash," Construction and Building Materials 29, 541-547. DOI:

10.1016/j.conbuildmat.2011.11.005

Zarina, Y., Al Bakri, A. M., Kamarudin, H., Nizar, I. K., and Rafiza, A. R. (2013). "Review on the various ash from palm oil waste as geopolymer material," Reviews on Advanced Materials Science 34(1), 37-43.

Zhang, Z., Han, Z., and Sheng, C. (2016). "Feasibility evaluation of biomass fly ashes from power station using as fertilizer," Transactions of the Chinese Society of Agricultural Engineering 32(7), 200-205. DOI: 10.11975/j.issn.10026819.2016.07.028

Zheng, R., Ren, Z., Gao, H., Zhang, A., and Bian, Z. (2018). "Effects of calcination on silica phase transition in diatomite," Journal of Alloys \& Compounds757, 364-371. DOI: 10.1016/j.jallcom.2018.05.010

Zhu, J., Tang, C., Wei, J., Li, Z., Laipan, M., He, H., Liang, X., Tao, Q., and Cai, L. (2017). "Structural effects on dissolution of silica polymorphs in various solutions," Inorganica Chimica Acta 471, 57-65. DOI: 10.1016/j.ica.2017.10.003

Zhu, Y., Hu, J., Yang, W., Zhang, W., Zeng, K., Yang, H., Du, S., and Chen, H. (2018). "Ash fusion characteristics and transformation behaviors during bamboo combustion in comparison with straw and poplar," Energy \& Fuels 32(4), 5244-5251. DOI: 10.1021/acs.energyfuels.8b00371

Article submitted: September 18, 2018; Peer review completed: October 12, 2018; Revisions accepted: December 10, 2018; Published: December 12, 2018.

DOI: 10.15376/biores.14.1. 977-995 